\title{
Commentary Noninvasive mechanical ventilation during the weaning process: facilitative, curative, or preventive?
}

\author{
Massimo Antonelli and Giuseppe Bello
}

Policlinico Universitario A. Gemelli, Università Cattolica del Sacro Cuore, Largo A. Gemelli 8, 00168 Rome, Italy

Corresponding author: Massimo Antonelli, m.antonelli@rm.unicatt.it

Published: 21 April 2008

Critical Care 2008, 12:136 (doi:10.1186/cc6853)

This article is online at http://ccforum.com/content/12/2/136

(c) 2008 BioMed Central Ltd

See related research by Trevisan et al., http://ccforum.com/content/12/2/R51

\begin{abstract}
To avoid the complications associated with endotracheal intubation, noninvasive positive-pressure ventilation (NPPV) has been proposed in the management of ventilator weaning in patients with acute respiratory failure (ARF) of various etiologies. Several studies have been performed to assess the benefit of NPPV in various weaning strategies, including permitting early extubation in patients who fail to meet standard extubation criteria (facilitation use), avoiding reintubation in patients who fail extubation (curative use), and preventing extubation failure in nonselected and selected patients (preventive use). NPPV has been successfully used in facilitating early extubation, particularly in patients with chronic obstructive pulmonary disease. In contrast, applying curative NPPV to treat postextubation ARF in nonselected populations may not be effective and could even be deleterious. Early use of NPPV was successful in preventing ARF after extubation, and decreased the need for reintubation in selected patients at risk of developing postextubation ARF. It is important that caregivers clearly differentiate among these application modalities of NPPV. The skills and expertise of both medical and nonmedical personnel are crucial predictive factors for the success of NPPV in the ventilator weaning process.
\end{abstract}

In the present issue of Critical Care, the use of noninvasive positive-pressure ventilation (NPPV) as a facilitative weaning technique has been clinically assessed by Trevisan and colleagues [1]. Sixty-five patients on invasive mechanical ventilation for $>48$ hours and with T-piece weaning trial failure were randomly assigned to receive bilevel NPPV by facemask or to continue the weaning process with invasive ventilation. Chronic obstructive pulmonary disease (COPD) aggravation, postoperative acute respiratory failure (ARF), and heart disease were the most frequent causes for the use of invasive ventilation support in both groups. The results of the trial showed that patients of the two groups had similar gas measurements throughout the study. The length of stay in the intensive care unit, the duration of mechanical ventilation after randomization, and the mortality were not statistically different when comparing the groups. Furthermore, the percentage of complications in the NPPV group was lower $(28.6 \%$ versus $75.7 \%$ ), with a lower incidence of pneumonia (3.6\% versus $45.9 \%$ ) and tracheotomy (0\% versus $18.9 \%$ ), than in the invasive ventilation group. These results led the authors to conclude that early extubation and NPPV is a valid alternative for ventilation in a group of heterogeneous patients that initially failed weaning.

NPPV is increasingly being proposed in the management of the ventilator weaning process, to avoid the complications of endotracheal intubation [2], and thereby to potentially lower morbidity and mortality rates in selected patients with ARF $[3,4]$.

The first report to assess the role of NPPV as a weaning technique dates back to 1992, when NPPV was successfully used in assisting the return of spontaneous breathing in a small group of 22 patients with chronic respiratory insufficiency and weaning difficulties [5]. Several trials have been performed thereafter to further determine the benefit of NPPV in permitting early extubation in patients who fail to meet standard extubation criteria [6-9] (facilitation technique), in avoiding reintubation in patients who fail extubation [10-13] (rescue or curative technique), and in preventing extubation failure in nonselected patients [14] and selected patients $[15,16]$ (preventive or prophylactic technique).

A recent meta-analysis of five studies enrolling a total of 171 patients was performed to investigate the role of NPPV in facilitating early extubation [17]. Compared with weaning strategies that involved invasive mechanical ventilation alone, noninvasive weaning was associated with a significant decrease in mortality, in the incidence of ventilator-associated 
pneumonia, and in the total duration of mechanical ventilation. In a subgroup analysis, the mortality benefit of NPPV was found to be greatest among patients with COPD.

Earlier trials on postextubation ARF in COPD patients [10] and in postoperative patients after lung resection [11] showed a significant decrease in the need for reintubation using NPPV compared with standard medical treatment. Despite these encouraging results, two subsequent studies evaluating the effectiveness of NPPV as a curative or rescue technique to treat the occurrence of postextubation ARF in nonselected populations failed to show improved outcomes $[12,13]$.

A number of trials have investigated the preventive or prophylactic use of NPPV immediately after extubation in avoiding extubation failure in comparison with standard medical therapy. In one early study on the indiscriminate use of NPPV in extubated patients, no significant difference in the rate of reintubation for either strategy was found [14]. In two subsequent studies, NPPV was found to prevent ARF after extubation and to decrease the need for reintubation in selected patients at risk of developing postextubation ARF $[15,16]$, especially those patients with hypercapnia during their spontaneous breathing trial [16]. It is important that caregivers clearly differentiate among these application modalities of NPPV (facilitative, curative and preventive) in the management of patients with tracheal intubation in clinical practice, and be aware of the benefit that each of these modalities can provide.

Trevisan and colleagues have made an important contribution to the continually evolving research on the use of NPPV in the management of weaning from mechanical ventilation. Their results extend the conclusions of other authors that NPPV can be a useful adjunct to conventional weaning strategies [6-9].

In their study, Trevisan and colleagues aim to assess the NPPV benefits in the weaning process of a heterogeneous group of patients. Despite the great interest of these findings for all practicing clinicians, the number of patients enrolled in the study was small, hence limiting the generalizability of its conclusions.

Currently available data suggest that the potential effectiveness of NPPV for facilitating ventilator weaning and early extubation varies across patient population, and that the benefit seems greatest for COPD patients [17]. Further studies are needed to better identify those subcategories of patients with non-COPD ARF who are most likely to benefit from NPPV during the weaning process and those who are at highest risk of adverse consequences.

The skills and expertise of both medical and nonmedical personnel represent some of the most important factors for the success of NPPV in the ventilator weaning process. It is crucial that caregivers can identify patients who are likely to benefit from early extubation with NPPV and exclude those patients for whom this approach would be unsafe. Once the decision to institute NPPV has been taken, an interface and ventilatory mode must be chosen, and close monitoring in an appropriate hospital location must be provided. Finally, when indicated, endotracheal intubation must be rapidly accessible.

\section{Competing interests}

The authors declare that they have no competing interests.

\section{References}

1. Trevisan CBE, Vieira SRR, Mechanical Ventilation Weaning Research Group: Noninvasive mechanical ventilation may be useful in treating patients that fail weaning from invasive mechanical ventilation: a randomized clinical trial. Crit Care 2008, 12:R51.

2. Pingleton SK: Complications of acute respiratory failure. $A m$ Rev Respir Dis 1988, 137:1463-1493.

3. Antonelli M, Conti G, Rocco M, Bufi M, De Blasi RA, Vivino G, Gasparetto A, Meduri GU: A comparison of noninvasive positive-pressure ventilation and conventional mechanical ventilation in patients with acute respiratory failure. $N$ Engl $J$ Med 1998, 339:429-435.

4. Antonelli M, Conti G, Bufi M, Costa MG, Lappa A, Rocco M, Gasparetto A, Meduri GU: Noninvasive ventilation for treatment of acute respiratory failure in patients undergoing solid organ transplantation. JAMA 2000, 283:235-241.

5. Udwadia ZF, Santis GK, Steven MH, Simonds AK: Nasal ventilation to facilitate weaning in patients with chronic respiratory insufficiency. Thorax 1992, 47:715-718.

6. Nava S, Ambrosino N, Clini E, Prato M, Orlando G, Vitacea M, Brigada $P$, Fracchia $C$, Rubini $F$ : Noninvasive mechanical ventilation in the weaning of patients with respiratory failure due to chronic obstructive pulmonary disease. A randomized, controlled trial. Ann Intern Med 1998, 128:721-728.

7. Girault C, Daudenthun I, Chevron V, Tamion F, Leroy J, Bonmarchand G: Noninvasive ventilation as a systematic extubation and weaning technique in acute-on-chronic respiratory failure: a prospective, randomized controlled study. Am J Respir Crit Care Med 1999, 160:86-92.

8. Kilger E, Briegel J, Haller M, Frey L, Schelling G, Stoll C, Pichler $B$, Peter K: Effects of noninvasive positive pressure ventilatory support in non-COPD patients with acute respiratory insufficiency after early extubation. Intensive Care Med 1999, 25: 1374-1380.

9. Ferrer M, Esquinas A, Arancibia F, Bauer TT, Gonzalez G, Carrillo A, Rodriguez-Roisin R, Torres A: Noninvasive ventilation during persistent weaning failure: a randomized controlled trial. $\mathrm{Am} \mathrm{J}$ Respir Crit Care Med 2003, 168:70-76.

10. Hilbert G, Gruson D, Portel L, Gbikpi-Benissan G, Cardinaud JP: Noninvasive pressure support ventilation in COPD patients with postextubation hypercapnic respiratory insufficiency. Eur Respir J 1998, 11:1349-1353.

11. Auriant $I$, Jallot $A$, Hervé $P$, Cerrina J, Le Roy Ladurie F, Fournier $\mathrm{JL}$, Lescot B, Parquin F: Noninvasive ventilation reduces mortality in acute respiratory failure following lung resection. $A m J$ Respir Crit Care Med 2001, 164:1231-1235.

12. Keenan SP, Powers C, McCormack DG, Block G: Noninvasive positive-pressure ventilation for postextubation respiratory distress: a randomized controlled trial. JAMA 2002, 287:32383244.

13. Esteban A, Frutos-Vivar F, Ferguson ND, Arabi $Y$, Apezteguía $C$, González M, Epstein SK, Hill NS, Nava S, Soares MA, D'Empaire G, Alía I, Anzueto A: Noninvasive positive-pressure ventilation for respiratory failure after extubation. $N$ Engl $J$ Med 2004 , 350:2452-2460.

14. Jiang JS, Kao SJ, Wang SN: Effect of early application of biphasic positive airway pressure on the outcome of extubation in ventilator weaning. Respirology 1999, 4:161-165.

15. Nava S, Gregoretti C, Fanfulla F, Squadrone E, Grassi M, Carlucci A, Beltrame F, Navalesi P: Noninvasive ventilation to prevent 
respiratory failure after extubation in high-risk patients. Crit Care Med 2005, 33:2465-2470.

16. Ferrer M, Valencia M, Nicolas JM, Bernadich O, Badia JR, Torres A: Early noninvasive ventilation averts extubation failure in patients at risk: a randomized trial. Am J Respir Crit Care Med 2006, 173:164-170.

17. Burns KE, Adhikari NK, Meade MO: A meta-analysis of noninvasive weaning to facilitate liberation from mechanical ventilation. Can J Anaesth 2006, 53:305-315. 